\title{
Integration of a Multilevel Transport System Model into Sustainable Urban Mobility Planning
}

\author{
Romanika Okraszewska ${ }^{1, *(\mathbb{D})}$, Aleksandra Romanowska ${ }^{1}$ (1), Marcin Wołek ${ }^{2}$, \\ Jacek Oskarbski $^{1}$ (D), Krystian Birr ${ }^{1}$ (D) and Kazimierz Jamroz ${ }^{1}$ (D) \\ 1 Faculty of Civil and Environmental Engineering, Gdansk University of Technology, 80-233 Gdańsk, Poland; \\ aleksandra.romanowska@pg.edu.pl (A.R.); jacek.oskarbski@pg.edu.pl (J.O.); krystian.birr@pg.edu.pl (K.B.); \\ kazimierz.jamroz@pg.edu.pl (K.J.) \\ 2 Faculty of Economics, University of Gdansk, 81-824 Sopot, Poland; mwol@wp.pl \\ * Correspondence: romanika.okraszewska@pg.edu.pl; Tel.: +48-58-347-27-31
}

Received: 30 December 2017; Accepted: 6 February 2018; Published: 11 February 2018

\begin{abstract}
When planning their transport policy, cities usually focus on developing sustainable transport systems and reducing the negative consequences of transport. One way to deliver transport policies is to use the Sustainable Urban Mobility Plan (SUMP), a strategic document designed to meet the demand for mobility whilst ensuring adequate quality of life for the residents. The process of Sustainable Urban Mobility Planning (SUMP process) can be supported by using a transport model. The objective of this article is to analyse the efficacy of the Multilevel Model of Transport Systems - referred to by its acronym, MST—-for the SUMP process. With its ability to represent the transport system's behaviour depending on the level of detail, the MST can significantly benefit the SUMP process. The proposed concept of integration of the MST into the SUMP process has already been tested and applied in delivering Gdynia's (Poland) SUMP. The paper suggests ways to use the MST at different levels of planning and modelling and describes the outcomes. Using the multilevel structure helps to fully realise the transport model's potential to improve the effectiveness of urban mobility planning. The conclusions show that the methods proposed in the article are worthwhile and cities should consider them when planning the SUMP process.
\end{abstract}

Keywords: Sustainable Urban Mobility Planning; SUMP; multilevel transport model

\section{Introduction}

In the early 20th century only sixteen of the world's cities had exceeded a million population. Since 1950 that number has increased very rapidly with as many as 411 cities exceeding 1,000,000 population in 2010 [1]. It is estimated that by 2050 cities will have attracted $70 \%$ of global population causing a threefold increase in urban trips [2]. As urban mobility grows, more problems emerge, especially when cars are the main growth accelerator. In 2015 there were more than 250 million passenger cars in EU countries [3]. It is estimated that by 2035 worldwide that number will double and go from $900 \mathrm{~m}$ in 2015 to 1.8 billion [4].

Growing motorisation causes congestion, emissions, noise, takes up land and affects road safety. The result are environmental, economic and social costs [5]. In the European Union alone the total external costs of transport (congestion, air quality, accidents, noise, $\mathrm{CO}_{2}$ emissions) in urban areas reach EUR 230 billion [6].

While urban mobility is local in character, failure to address this phenomenon may have global consequences. If properly balanced, urban mobility can deliver on its potential to reduce the negative effects of transport. But there are some serious barriers to tackle [7]. The European Commission in its Green Paper [8] identified the main challenges of growing urban transport. They are to: 
- improve urban traffic flows by optimising the use of the private car, promoting active mobility (walking, cycling), sustainable freight transport,

- increase the use of Intelligent Transport Systems (ITS) within urban transport,

- reduce the negative impact of transport on the environment by using modern technologies and alternative sources of energy, promoting eco-driving and restricting traffic,

- improve accessibility and integration of urban transport including sustainable land use planning,

- improve the safety and reliability of urban transport,

- change transport behaviour and how urban communities perceive transport.

Changing transport behaviour is particularly difficult and time-consuming. If mobility means the ability to move about and make transport choices, the role of urban mobility management [9] is to stimulate informed choices and decisions. This can be achieved by e.g., harmonising land use planning and transport planning [10], in particular by delivering the concept of compact development in urban areas. This is designed to reduce the use of urban space by transport and bring down the demand for transport and car-dependence [11-13]. Lifestyle changes to adjust to new systems should be geared towards the use of alternative modes of transport rather than the car and to reduce the demand for transport [14-16]. These changes are increasingly often accompanied by a transition, focused on the energy efficiency of transport means, including electromobility [17].

The European Commission's proposed tool to achieve sustainable urban mobility is the Sustainable Urban Mobility Plan (SUMP), a document that sets the framework for urban mobility planning and management and is the result of a participative Sustainable Urban Mobility Planning process (SUMP process). The objective of the process should be to improve the urban quality of life by ensuring a safe, reliable, integrated, multi-modal, effective and environment-friendly transport system [18]. Because it is such a comprehensive process, it needs support from methods and tools as recommended by the European Commission. One of the tools is a transport model designed to enhance planning and decision-making and stakeholder communications. For planning purposes the most widely used models are macroscopic models (e.g., transport and land use integrated model or four step travel demand model [18-20]). When they are used for SUMP purposes, however, the analyses are usually confined to urban scenario development and evaluation without making a full use of the tool's potential when e.g., selecting the most effective actions or drafting a monitoring plan.

A transport model is undoubtedly a valuable tool for mobility planning. It supports advanced and reliable transport analyses and decision-making. With its multiple applications that can serve a variety of municipal bodies, it can support a range of activities from planning transport systems to local traffic management at the operational level. Many cities do not have a transport model which is probably a result of the anticipated costs to build the model and maintain it. Transport models need money, people and time and decision-makers do not always appreciate the benefits of transport models.

The objective of the article is to analyse and present ways to use the Multilevel Model of Transport Systems (referred to by its acronym, MST) during the SUMP process. Using the model, it is possible to map out the behaviour of the transport system and its users on a macro, meso and micro scale. It also supports strategic, tactical and operational analyses. The paper proposes a method for integrating the model into the SUMP process. The method was used in Gdynia which conducted its SUMP process between 2012 and 2016. The paper identifies the MST's potential and the outcomes when it is used at different levels of planning (strategic, tactical, operational) and modelling (macro, meso, microscopic), e.g., to assess scenarios or select effective actions.

Section 2 explains the processes of planning sustainable urban mobility and the transport model as a tool to be used in the process. Section 3 proposes a method for integrating the MST into the SUMP process. The actual application and results are given in Section 4 . The final section discusses and summarises the main findings and formulates recommendations on how cities embarking on the SUMP process should use the model for planning mobility. 


\section{SUMP and Multilevel Transport Model-An Overview}

\subsection{Sustainable Urban Mobility Planning Process}

Sustainable Urban Mobility Plan is a strategic document designed to meet the demand for mobility of the city's residents and businesses, including those outside the city and improve the urban quality of life [18]. The document sets out strategic urban mobility objectives and policies at the tactical level and integrates operational level actions. For almost a decade the European Commission has been actively promoting multi-annual mobility plans and supporting cities with their sustainable goals and objectives [21]. Cities can benefit substantially from the technical frameworks and SUMP guidelines [18,21].

Mobility should be viewed comprehensively and fit in with the broader context of development strategy. It should address the problems of transport, land use, property management, environmental protection, social policy, health, safety and economic growth [7]. Because urban mobility has multiple aspects, a balance is needed between the economic, social and spatial areas [22]. If the idea of sustainable urban mobility is to be delivered, it must take account of all types of urban transport (transport of people and freight) and their integration, user behaviour and the opportunities offered by new technologies (ITS-Intelligent Transport Systems, ICT-Information and Communications Technologies). Sustainable urban mobility should deliver an accessible, sustainable, safe, integrated, environment friendly and efficient system meeting the mobility needs of citizens, businesses and industry [21].

The SUMP document is just as important as the process that helped to develop it. The SUMP process should involve different groups of stakeholders, ensure a participatory approach, have a long-term vision and a clear action plan designed to promote a sustainable and integrated development of all forms of transport. The Plan requires regular monitoring. As well as tackling transport and land use relations, sustainable urban mobility is very much a community-based decision-making process involving a wide spectrum of stakeholders [23]. It needs political support and strong community and stakeholder engagement [24] with decision-support tools and methods playing an important role in the process [25-28].

Sustainable urban mobility is delivered through strategies designed to reduce trips and include land-use policy measures focussed on distance reduction, transport policy measures to trigger long-term changes in modal-split and technological innovation to increase efficiency $[7,29]$.

As set out in the guidelines for SUMP development and delivery [18] the process includes eleven consecutive steps within four basic stages: preparation, goal setting, elaboration and final implementation (Figure 1).

The European Commission [18] recommends the use of different methods and tools to make the process more effective which includes support for planning and decision-making using, e.g., transport models. Generated by a transport model, the results can provide the necessary insight into the existing or future transport problems, a consequence of changing mobility patterns, urban spatial development and transport projects. Transport models can provide the much needed planning and decision-making support [30] and supplement engineering knowledge and practice with results of simulations conducted in the model. This suggests the importance of integrating these models into the SUMP cycle. However, mobility can still be planned, even if there is no model. Building a new model or updating it requires funding and skilled staff. How big the costs will be depends on the complexity of the model and the size of the city, and can sometimes be a real barrier. Human and financial resources will be needed to maintain and improve the model. As a result, the decision to work with a model should only be made if the costs and benefits are properly understood. While the SUMP process can be carried out using solutions other than the model, EU reporting requirements mean that comprehensive implementations must be based on transport models to help to calculate and compare economic indicators [31]. 


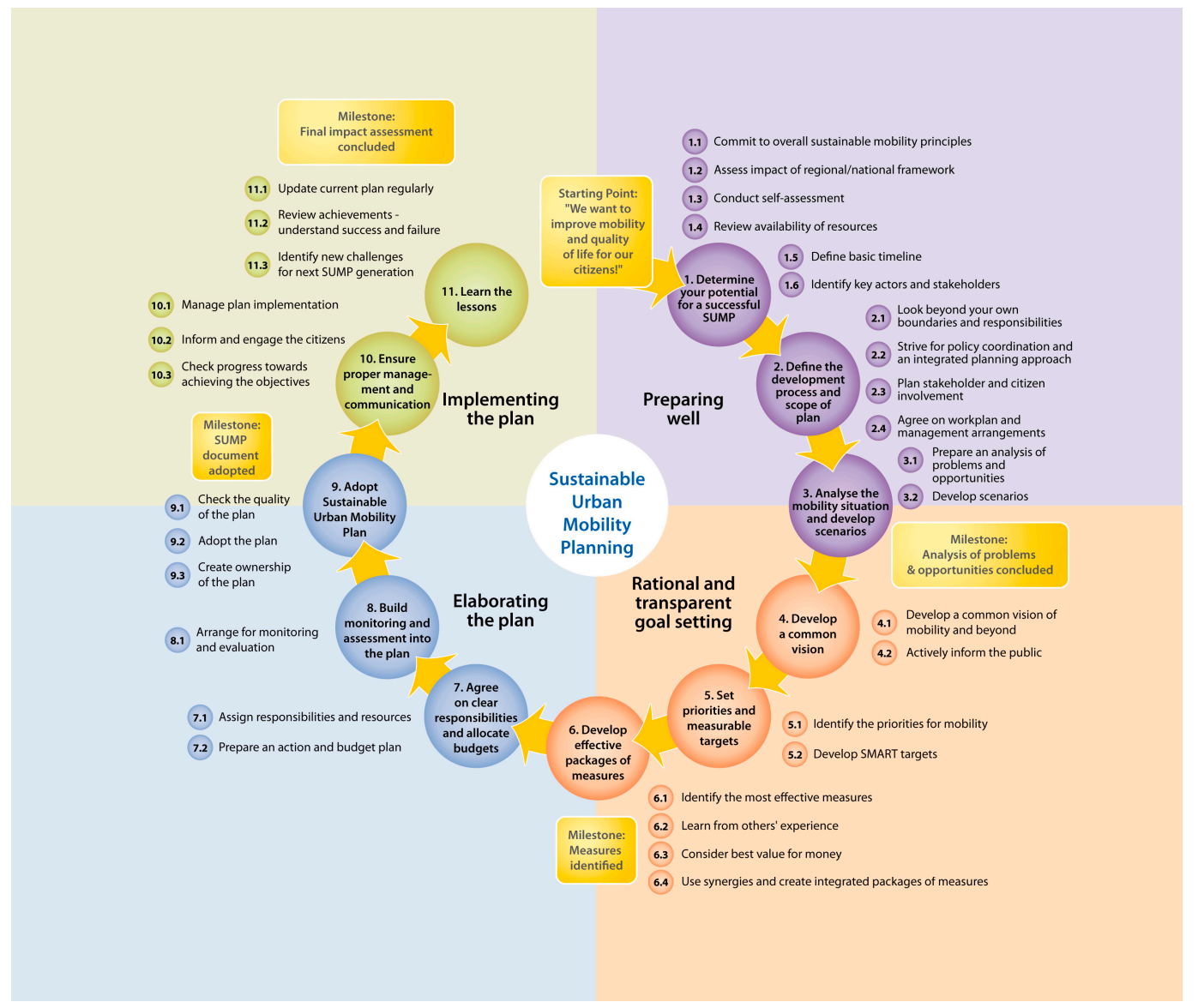

Figure 1. SUMP process diagram. Source: [18].

While many European cities have their own models [32,33], they do not always use them to their full potential [30]. One reason for this is decision-makers' lack of understanding of what transport models have to offer. In addition, some transport models lack a multilevel structure. Many cities use macroscopic models only. Others use different levels (macro, meso, microscopic) but stop short of integrating them, leaving them unable to exchange data. This was the case in how the US managed its transport (including urban transport) [34]. In many of the cases described in [34] software packages by different manufacturers were used without integrating them at data exchange levels (lack of reference points). As a consequence, automatic data flows between different levels of modelling were not possible, preventing the results from being used by different transport authorities. Lack of cooperation between the relevant actors (who use the models for planning, implementation, traffic and public transport management) is another problem [30]. The literature offers a limited number of examples of how traffic models were used in the SUMP process with most of them applied to develop urban mobility scenarios only $[18,35,36]$.

\subsection{Multilevel Model of Transport Systems}

A transport model helps to represent the movement of people and goods in a transport network within an area having certain socio-economic and land use characteristics [31,37]. It is a tool that helps to simulate the behaviour of a city's transport system and its users over time and the response to changes in transport supply and demand. There was extensive research on mathematical modelling of trips and vehicle flows in the second half of the previous century [38-40] producing a number of software packages that help to build transport system models for an area or a road and to forecast traffic (e.g., EMME, INTEGTARION, VISUM, SATURN, TRIPS, AIMSUN etc.). 
Models may differ on the scope they cover. Fully integrated multilevel structures are quite rare. One of the exceptions is the city of London, well known and described in the literature [41-43]. London adopted the following division of modelling and modelling tools [41]:

- London Strategic Model (LTS): Output-Demand data, Input-Network description data,

- Cordon Area Model (VISUM/SATURN): Output-Network description data, Driver route choice, Input—Demand data, Signal timing data, Junction Capacity,

- Micro-simulation model (VISSIM/PARAMICS): Output—Signal timing data, Junction Capacity Traffic flows, Input: Driver route choice, Optimized signal settings,

- Local Area Model (LinSig, TRANSYT, OSCADY): Output: Optimized signal settings, Input: Traffic flows.

The London model served as a reference for Gdynia which also built its integrated multilevel model. The assumptions of the model and the process of its development are described in the Report on the traffic model development for SUMP (Document S3 in Supplementary Materials). Gdynia chose a three-level structure with macro, meso and microscopic layers (Figure 2). While the scale of the cities is vastly different, the overall concept of how the models are built and used are similar. The actual modelling method and how the different levels are used depends on the transport treatment in question-the multilevel model supports a flexible approach to the analytical process.

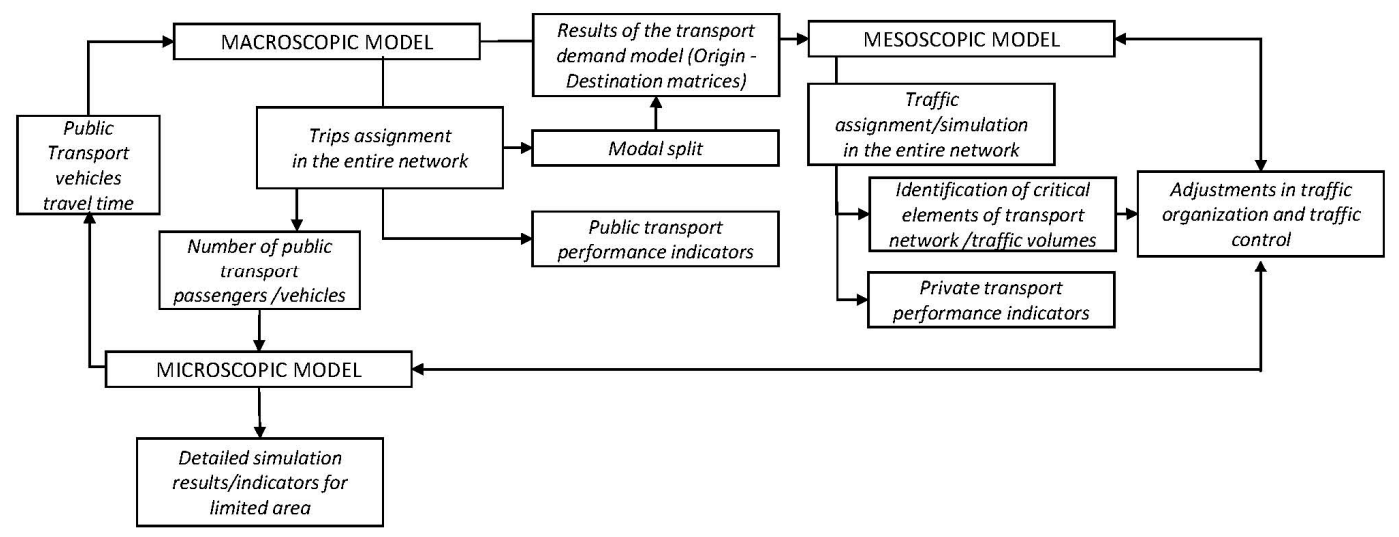

Figure 2. Diagram of Multilevel Model of Transport Systems (MST).

Where land use and sustainable transport plans are concerned, macroscopic models prevail $[18,19]$. Where more detail is required, meso and microscopic models are indispensable because they help to simulate traffic flows together with their profiles, platoon dispersion, averaged traffic parameters such as queues and delays, saturation flows, etc. (mesoscopic models) and behaviour and interactions between individual road users (microscopic models).

Hierarchical models have a broad range of applications. The layers represent specific areas and levels of management [41]. A multilevel model consists of three integrated macro, meso and microscopic layers. The data it supplies are used to conduct different tasks specific for the life cycle of the transport system or transport facility and help with optimal decision-making. Planning, transport facility feasibility studies, proposed traffic layouts and junction and interchange geometry are some of the other areas that benefit from the data supply. The model can also support traffic management and planning systems and public transport and traffic managers [44]. It is a source of data on traffic parameters and transport system efficiency indicators (i.e., kilometres travelled, journey time, capacity usage, fuel consumption, exhaust emissions, etc.) for planning and operational purposes.

The structure of the model is largely determined by the software. The choice of software usually depends on the experience users have had with previous programmes and, as a result, the skills available. Figure 2 shows a diagram of the flow of data used for analysis across the levels (macro, 
meso and micro). Although devised for Gdynia, the solution can be adapted regardless of the region's or city's current software.

Thanks to its multilevel structure, the model supports strategic, tactical and operational analyses. Because multilevel model is hierarchical, specific models can feed data to one another which ensures transparency of the outcomes, regardless of the level of modelling [45].

Figure 2 shows how the model's multilevel structure is used for Gdynia's SUMP analyses. The flow of data between the levels is ensured thanks to the references (uniform numbering of transport zones, nodes and links between them). The macroscopic model is the base for analysing changes in transport demand (new land use rules and new socio-economic and demographic data), modal split and modal shift with road users changing between public transport and the car as a result of improvements. The macroscopic model is also the basis for early analysis of traffic distribution and trips by public transport and the car. Calculated in the macroscopic model, trip matrices are the basis for traffic distribution in the mesoscopic model (distribution adjusted for details of traffic organisation). The mesoscopic model helps to identify the critical elements of the transport network such as junction entry queues including blocking back. It also helps to analyse ways to improve traffic efficiency (lanes at junction entry, corrections to signalization programmes, use of different junction types, adding signalization, etc.) which may improve transport (higher efficiency or better road safety). The analyses look at the effects a measure has on the city's entire transport network. Once recommended, new traffic layouts can be micro-simulated. Micro-simulation receives private transport data from the mesoscopic model with public transport data provided by the macroscopic model. The role of the microscopic model is to help with a detailed analysis of how a proposed measure will impact the local level and with understanding the necessary changes in e.g., traffic control (the resulting changes can be fed into the mesoscopic model again for a repeat analysis). In mesoscopic and microscopic models traffic distribution is adjusted as well as trip times between sections of public and private transport. The macroscopic model is then updated with the new parameters and a repeat distribution is conducted which helps to modify the trip matrices of the modes (modal shift). This is how key network performance indicators can be obtained for public transport. Private transport indicators are obtained after the meso model is applied again.

At the model's strategic level the analyses help to develop better transport policies and planning and network studies. For modelling purposes the macroscopic model is used (e.g., the four step model) [46]. The model has two basic elements, i.e., the transport network model and the trip demand model.

The model's tactical level helps to conduct analyses which supply data for decision-makers' policy decisions (transport network and transport corridor studies, feasibility studies), proposed traffic layouts and traffic control strategies, effectiveness evaluations of planning and traffic management analyses. Thanks to its ability to estimate the outcomes of new measures, the model is helpful with analysing proposed transport system improvements. Analyses are conducted at the mesoscopic level and cover the transport network (the entire city or a selected part), a series of road or street sections and public transport lines.

The model's operational level supports analyses and supplies data for new detailed street network proposals, traffic layouts, traffic control programmes including public transport priority, traffic control logic to give priority to pedestrians and cyclists and visualisation of the proposed improvements. Analyses can cover specific road or street sections, sections of public transport lines, a series of junctions or a single junction. Analyses are conducted at the micro level. As well as helping to verify and present the outcomes generated by macro and mesoscopic models, the model helps to visualise the effects of proposed measures on traffic in a specific area.

\section{Methodology}

The primary reason for integrating the transport model into cities' mobility planning efforts is to provide maximal support to the SUMP process throughout its phases. The macroscopic transport 
model itself is a major contributor. However, extending the model with meso and microscopic layers can bring additional benefits to the process, as these support planning efforts with analyses that offer different levels of detail appropriate for the planning required.

The objective of integration is to ensure a good match between the model's capacity and the stages and steps of the SUMP process (Figure 1). The different levels of the model apply to the different stages of the process (Table 1). The utility of the model at "Preparing well" is that scenarios can be developed using the macroscopic model with possible additions made using the mesoscopic model. At "Rational and transparent goal setting" each level provides different data for defining measurable goals and analysing and evaluating the effectiveness of the solutions (see the example in Section 4.3). The microscopic model provides the value added, i.e., visualisation of data, used during public consultation involving a variety of stakeholders (see Section 4.4). "Elaborating the plan" is linked to "Rational and transparent goal setting," because analysis results are used to develop a monitoring plan. "Implementing the plan" is the final stage which involves regular monitoring to keep track of the progress and select new indicators, if the plan were to be modified.

Table 1. Potential scope of how the transport model can be used at the different SUMP stages.

\begin{tabular}{cccc}
\hline \multirow{2}{*}{ Stages of SUMP } & \multicolumn{3}{c}{ Multilevel Transport Model } \\
\cline { 2 - 4 } & Macroscopic & Mesoscopic & Microscopic \\
\hline Preparing well & $X$ & $X$ & \\
Rational and transparent goal setting & $X$ & $X$ & $X$ \\
Elaborating the plan & $X$ & $X$ & $X$ \\
Implementing the plan & $X$ & $X$ & $X$ \\
\hline
\end{tabular}

Figure 3 gives a detailed concept of how the MST is integrated within the SUMP process. Having a transport model prior to the SUMP process is strongly recommended. If no model is available, it is advisable to plan for one in the SUMP project's schedule and budget. An existing model can be adapted to SUMP process needs by making sure that it is up-to-date and consistent with the timeline. It is important to define the scope of the model (modelling level, means of transport) and ensure that it can be used effectively (defining how the model will be used if controlled by a different body, ensuring specialist help to run the software). While the city's transport model can visually represent the effects of proposed changes, this varies depending on its complexity. Where possible, such graphic representations can be used during public consultation or as support for the decision-making process. Because the model's potential is known early on, during the preparatory stage of the SUMP process, stakeholder involvement and public participation can be planned well in advance and take account of the model's capacity to support that process. The model's greatest utility for the SUMP process is that it provides data on the operation of the transport system, the assessment stage and scenario selection and directions of the transport system's development. When used at the "Goal setting stage," the model's most important objective is to help with selecting the most effective measures for the targets. The model has different layers that are used to assess the effectiveness of the measures in relation to how detailed they are (scale of the measure, measures of effectiveness). The basic layer is the macro model which can operate as an independent model or have extra meso and micro layers added to it. Thanks to its multiple levels, the model offers new options such as evaluating detailed changes to traffic organisation and presenting them in an attractive visual form. Because the models exchange simulation data with one another, the outcomes are kept transparent regardless of the level of modelling. Produced by the model, the effectiveness evaluation is then used as a basis for defining indicators to monitor and evaluate the measures. Monitoring indicators help to define the targets in line with the SMART concept (Specific, Measurable, Achievable, Relevant, Time-bound). This ensures that monitoring and evaluation of the targets are rational and transparent. The SUMP process is finalised when decision-makers have adopted a formal document which is also the city's commitment to implement it. At this stage, modelling outcomes can help to argue in favour of the proposal when addressing councillors and persuading them to adopt the document. 


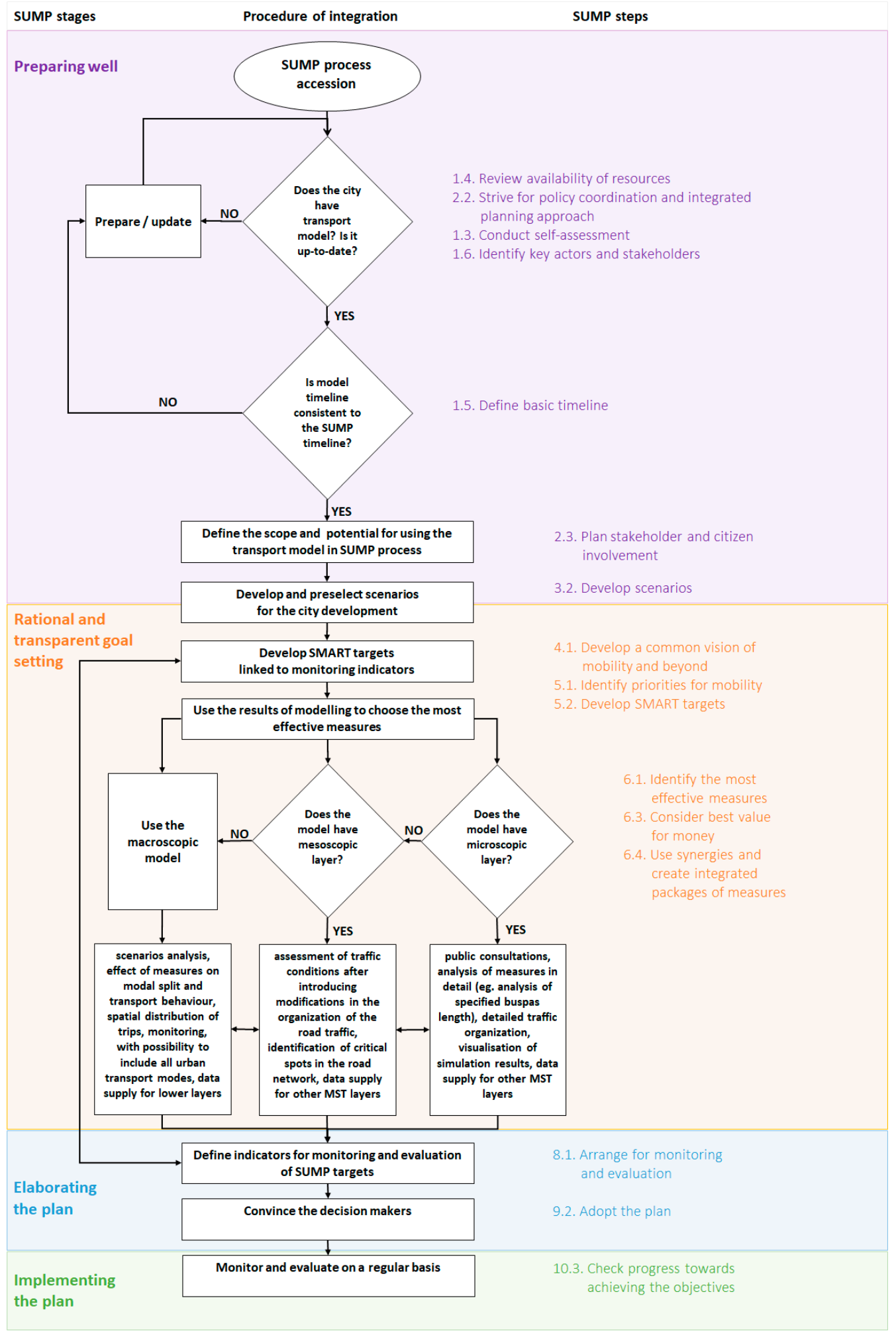

Figure 3. Concept of MST integration into SUMP process.

The SUMP process involves a number of levels and is designed to set out the city's development vision (strategic level), long-term goals and policies (strategic, tactical level) and short-term action plans (operational level). Thanks to its many levels, the MST can be used in the successive stages of 
the SUMP process (Table 1) and support the planning process at the strategic, tactical and operational levels (Table 2) which alternate during the SUMP cycle.

Table 2. The use of MST in particular SUMP steps.

\begin{tabular}{|c|c|c|c|}
\hline \multirow{2}{*}{ Planning Levels } & \multicolumn{3}{|c|}{ Modelling Level-Multilevel Transport Model } \\
\hline & Macroscopic & Mesoscopic & Microscopic \\
\hline Strategic & $\begin{array}{l}\text { Define basic timeline (step 1.5) } \\
\text { Strive for policy coordination and } \\
\text { integrated planning approach } \\
\text { (step 2.2) } \\
\text { Develop scenarios (step 3.2) } \\
\text { Develop a common vision of } \\
\text { mobility and beyond (step 4.1) }\end{array}$ & Develop scenarios (step 3.2) & \\
\hline Tactical & $\begin{array}{l}\text { Conduct self-assessment (step 1.3) } \\
\text { Review availability of resources } \\
\text { (step 1.4) } \\
\text { Identify key actors and } \\
\text { stakeholders (step 1.6) } \\
\text { Plan stakeholder and citizen } \\
\text { involvement (step 2.3) } \\
\text { Develop SMART targets (step 5.2) }\end{array}$ & $\begin{array}{l}\text { Conduct self-assessment } \\
\text { (step 1.3) } \\
\text { Plan stakeholder and citizen } \\
\text { involvement (step 2.3) } \\
\text { Develop SMART targets } \\
\text { (step 5.2) }\end{array}$ & $\begin{array}{l}\text { Conduct self-assessment } \\
\text { (step 1.3) } \\
\text { 2.3.Plan stakeholder and } \\
\text { citizen involvement (step 2.3) } \\
\text { 5.2.Develop SMART targets } \\
\text { (step 5.2) }\end{array}$ \\
\hline Operational & $\begin{array}{l}\text { Identify the most effective } \\
\text { measures (step 6.1) } \\
\text { Consider best value for money } \\
\text { (step 6.3) } \\
\text { Use synergies and create } \\
\text { integrated packages of measures } \\
\text { (step 6.4) } \\
\text { Arrange for monitoring and } \\
\text { evaluation (step 8.1) }\end{array}$ & $\begin{array}{l}\text { Identify the most effective } \\
\text { measures (step 6.1) } \\
\text { Consider best value for } \\
\text { money (step 6.3) } \\
\text { Use synergies and create } \\
\text { integrated packages of } \\
\text { measures (step 6.4) } \\
\text { Arrange for monitoring and } \\
\text { evaluation (step 8.1) }\end{array}$ & $\begin{array}{l}\text { Identify the most effective } \\
\text { measures (step 6.1) } \\
\text { Consider best value for } \\
\text { money (step 6.3) } \\
\text { Use synergies and create } \\
\text { integrated packages of } \\
\text { measures (step 6.4) } \\
\text { Arrange for monitoring and } \\
\text { evaluation (step 8.1) }\end{array}$ \\
\hline
\end{tabular}

The strategic level of mobility planning involves setting out the city's vision and selecting development scenarios (steps 3.2, 4.1) for a specific time horizon and defining an appropriate timeline (step 1.5). The planning process at the strategic level reaches its climax when the SUMP document is adopted (step 9.2). This level of planning receives the support of macro level analysis results. This helps to ensure that the development of the transport system goes hand in hand with the land use policy (step 2.2), that the right development scenario is selected (step 3.2) to optimise the use of the transport network and identify priorities for mobility (step 5.1). At the strategic level, it is advisable to pre-analyse the scenarios using the mesoscopic model. Thanks to this, the critical points in the transport network can be identified and improved if they should emerge as a result of the scenario.

At the tactical level, it is important to establish whether the city already has a transport model. It involves a self-assessment and a review of readiness for the SUMP process (steps 1.3, 1.4, 1.6). Where a model is not available, developing one must be included in the SUMP process's schedule and budget. The composition of the SUMP process team must ensure easy access to the results of the model. This is best achieved by securing the direct involvement of bodies responsible for model development and maintenance. With the extended structure of the model, plans can be made for how to use it further in the SUMP process (step 2.3). Central to the SUMP process at the tactical level is defining how the city should develop using a specific scenario and the vision and goals (step 5.2) to be achieved by the city through SUMP development and implementation.

The operational level of planning involves selecting the most effective measures (step 6.1) which will help to deliver the tactical level's targets and the strategic level's vision. Evaluation can be done at each MST layer and the results will correspond to the desired level of detail. Based on analyses, the measures and packages of measures can be evaluated for their effectiveness (step 6.3) and the indicators selected for this purpose will be used to monitor and evaluate the process (step 10.3). 
The unique value of the model at the operational level is that the effects of changes can be visualised which is invaluable for better communication between everyone involved and provides the much-needed support during public consultation.

The significance of planning levels within the SUMP process may differ from city to city and reflect different spatial, social, economic and political factors. As an example, a smaller town may give priority to operational measures whilst bigger cities may take the strategic approach to urban development and transport system.

\section{Results}

\subsection{Case Study—Integrated SUMP Approach in Gdynia}

A larger scale application of the MST within the SUMP process was conducted in Gdynia, a city with a population of nearly 250,000 in north Poland. Gdynia was Poland's first city to have developed and implemented the multilevel model for the purposes of the SUMP process using the methodology presented in Section 3.

The result of the SUMP process, Gdynia's mobility plan reflects the city's character of a young town. Established in 1926 to support the construction of a new sea port, today the city is part of a metropolitan area with a population of $1.5 \mathrm{~m}$. One of the consequences of its legacy is the layout of the city centre and the centrally located sea port with its dynamically growing cargo terminals.

Gdynia's basic challenges include the rapidly growing car traffic (with motorization rates increasing from 238 passenger cars/1000 population in 2002 to 567 in 2016) and sub-urbanisation processes. With dispersed origins and destinations of traffic and a loose built environment, car dependence is growing causing even more problems such as higher levels of congestion, emissions and noise. Trips in Gdynia by those aged 15-75 are mostly by car ( $57.8 \%$ of non-pedestrian trips in 2015). Public transport's share in modal split is nearly $40 \%$ with cycling representing app. $2 \%$ [47].

Gdynia's SUMP for the years 2016-2025 [48] (Document S1 in Supplementary Materials) is the outcome of work carried out under CIVITAS DYN@MO [49], an EU project implemented within 7th Framework Programme. Developed in accordance with the European Commission's guidance [18], the plan is an extended and revised sustainable transport plan developed for the years 2008-2015 under an EU project called BUSTRIP. The document covers a wide spectrum of issues and aims to ensure that all modes of urban transport are on equal footing. Developed with a strong engagement of a variety of stakeholders including public administration, education sector, transport companies and the residents, the plan sets out four strategic objectives:

(1) Attractive and safe urban space.

(2) Low-emission and integrated public transport.

(3) Rational transport choices.

(4) Effective urban freight transport.

Included in the document is an operational level action plan with revisions planned every 2-4 years. The first action plan is for the years 2016-2018.

Part of the CIVITAS DYN@MO project, in an effort to extend Gdynia's SUMP, the city's multilevel transport model was built. It covers private car traffic and public transport (car, bus, rail) but will ultimately include pedestrian and cycle trips as well (the city is currently expanding the model under the FLOW project).

The model covers all of Gdynia which is divided into 173 transport zones. Each is described with trip-generating variables such as: population, jobs, places of education, size of buildings divided by function and others. Gdynia's street network is represented in its entirety with links categorised based on technical class, cross-section, capacity and free-flow speed. The whole transport network is made up of more than 5500 links and more than 2100 nodes. To calculate the demand for trips and residents' transport behaviour in the 4-step model [50,51], functions were used that were calibrated on the basis 
of comprehensive traffic surveys conducted in the city of Gdańsk in 2009 as well as on Gdynia's 2013 survey of resident preferences and transport behaviour [47].

The model was applied at many of the SUMP process stages (Figure 3) and produced measurable indicators and evaluations. At the strategic level of planning the model was used e.g., to select the mobility scenario. At the operational level, it helped to evaluate the effectiveness of bus priority measures planned for the city's main streets. Sections 4.2 and 4.3 present selected results of MST-based analyses.

\subsection{Selecting the Mobility Scenario}

Because developing short-term and long-term forecasts has been increasingly more difficult, there is a growing trend to use scenarios. While some countries introduced scenarios into transport policy-making as early as the 1980s [52], companies were there first, with Shell pioneering the use of comprehensive strategic scenarios already in the mid-1970s [53].

When they are developed for mobility plans and transport policy purposes, scenarios use a variety of criteria. As an example, in Scandinavian countries the key criteria are related to energy and emissions [54].

Scenarios help to gain a better understanding of the combined effects of measures considered in the SUMP process. A visualisation of possible future situations offers a more objective assessment of the consequences of today's trends, on-going measures and new choices. By analysing the impacts of scenarios, we can be more realistic about the targets and monitoring indicators [55].

The scenarios for Gdynia were developed by looking at the potential mobility it has on its own and as part of the metropolitan core and analysing its internal and external development conditions. The scenarios are based on a matrix structure, a result of two factors each of which indicates the intensity of the phenomenon (low/high). Key to developing urban mobility scenarios are data availability and reliability. The reason why scenarios based on two criteria are popular is their transparency, relative ease of parameter selection and a small number of highly differentiated scenarios [45]. The factors were selected in a trade-off between a precise definition and description of a state and the ability to quantify it (concrete indicators to help with monitoring).

The scenarios are a result of two key aspects which represent challenges (dilemmas) of how to balance urban development and the mobility of the population. They are:

- Urban modal split representing the transport behaviour of Gdynia residents. Trips are influenced by external factors (e.g., cost of fuel, government taxation policy towards car owners, life style, urban sprawl) and internal factors (e.g., local transport policy, spatial and transport system, competitiveness of urban transport, priorities for pedestrians and cyclists). This is clearly reflected by the share of car trips in overall urban trips.

- Mobility of the population expressed with an average number of all trips in a unit of time. As regards Gdynia, reducing residents' trips is quite a challenge due to the city's spatial layout, the attractiveness of the city centre including the waterfront and the concentration of places of work and education.

Each of the above aspects should be measurable to ensure that the same parameters can be used over time for monitoring purposes.

With these aspects as reference, four states (situations) were defined to describe how Gdynia's sustainable mobility will develop mid- and long-term (Table 3).

The point of departure for the scenarios is 2015 . That year cars represented $51.5 \%$ of the modal split and public transport (bus, trolleybus, rail) share was 35.5\%. Cycling represented $1.6 \%$ and walking (over distances above $500 \mathrm{~m}$ ) accounted for $11 \%$ of overall trips. From Monday to Friday the statistical Gdynia resident carried out an average of 1.65 non-pedestrian trips daily [47]. Gdynia's total car kilometres travelled added up to $815.2 \mathrm{~m}$ vehicle kilometres in 2015. 
All scenarios were analysed against a traffic model specific to Gdynia (high share of freight generated by the port, central port location, development in the economic zone, proximity to areas that have high rates of urbanisation). The results suggest that key to reducing car vehicle kilometres is a modal shift and swapping the car for alternative modes (public transport, cycling and walking). Efforts should be taken to integrate the chain of trips, especially as regards cycling and public transport. Changing the number of trips is less important and it is believed that because the centre of Gdynia will continue to attract obligatory trips for work and education and optional trips (for recreation and leisure), efforts to change this element would not have much of an effect. As a consequence, limiting the role of the car in the everyday life of the people of Gdynia is of key importance and if this goal is to be achieved, the measures must be integrated and comprehensive [48].

Table 3. Comparison of urban mobility development scenarios within SUMP process.

\begin{tabular}{|c|c|c|c|}
\hline Scenario & $\begin{array}{l}\text { Assumption 1: The Share } \\
\text { of Car in Modal Split }\end{array}$ & $\begin{array}{l}\text { Assumption 2: General } \\
\text { Number of Trips }\end{array}$ & $\begin{array}{l}\text { Result: m veh-km } \\
\text { Travelled by Cars in } \\
\text { Gdynia in } 2025\end{array}$ \\
\hline $\begin{array}{l}\text { 1. Sustainable urban mobility in the } \\
\text { conditions of increasing number of } \\
\text { trips by citizens }\end{array}$ & decrease by $10 \%$ & increase by $5 \%$ & 710.7 \\
\hline $\begin{array}{l}\text { 2. Unsustainable urban mobility in } \\
\text { the conditions of increasing number } \\
\text { of trips by citizens }\end{array}$ & increase by $10 \%$ & increase by $5 \%$ & 1010.0 \\
\hline $\begin{array}{l}\text { 3. Sustainable urban mobility in the } \\
\text { conditions of decreasing number of } \\
\text { trips by citizens }\end{array}$ & decrease by $10 \%$ & decrease by $5 \%$ & 635.7 \\
\hline $\begin{array}{l}\text { 4. Unsustainable urban mobility in } \\
\text { the conditions of decreasing number } \\
\text { of trips by citizens }\end{array}$ & increase by $10 \%$ & decrease by $5 \%$ & 911.5 \\
\hline
\end{tabular}

Quantitative scenarios are difficult to develop because of the level of uncertainty in predicting future developments. Urban mobility depends on a variety of factors. They are both external and independent of the tools available to city authorities and internal. Some of them could be easily implemented with immediate results (parking policy, traffic reorganisation, attractive fares in public transport), while the effects of others may take a long time to emerge (change of lifestyle, results of consistent and sustainable spatial planning).

Thanks to the model, it was clear what the results would be if a specific scenario were to be implemented (Table 3). This can be seen in how traffic volumes would change within the city's transport network (Figure 4). That produced a good starting point for a discussion about goals, action plans and monitoring the delivery of Gdynia's SUMP.

\subsection{Analysing the Effectiveness of Bus Lanes on Selected Roads}

To exemplify how the multilevel traffic model was used in the SUMP process's operational level, the paper will look at dedicated bus lanes, how they were analysed and assessed for their relevance. The concept for dedicated bus lanes in Gdynia and detailed analyses results are presented in the Document S2 in Supplementary Materials. Work on the study methodology and bus lane practicality assessment included traffic indicators. Developed based on the literature, the indicators characterise traffic conditions on each street section and were used for assessing the effectiveness of the proposed measures. The indicators include:

- change in global journey time (passenger hours) of all urban transport network users-the indicator identifies the direct effectiveness of the measures such as time saved by transport network users,

- change in the share of public transport trips within the city-the indicator identifies the direct effectiveness of the measures and looks at the change in the attractiveness of trips for each mode,

- change in the share of public transport passengers for a street cross-section (includes the number of motor vehicles and their average occupancy) — this is to understand the relative significance of 
time lost by public transport passengers compared to other road users, an element that should be used to optimise time lost in view of sustainability,

- change in emissions-the indicator looks at environmental benefits that arise when vehicle-kilometres travelled, average traffic speed and vehicle delays change.

The analyses were conducted on the macro, meso and microscopic level. Macro and mesoscopic level analyses helped to calculate the degree to which bus lanes will change people's transport behaviour in terms of spatial distribution of trips, transport modes and new trip paths. Simulations were conducted to help calculate the change in global journey time of all users of the city's entire transport network, share of public transport trips in the city and for the cross-sections (Table 4). The data from the calculations were also used in the microsimulation model.

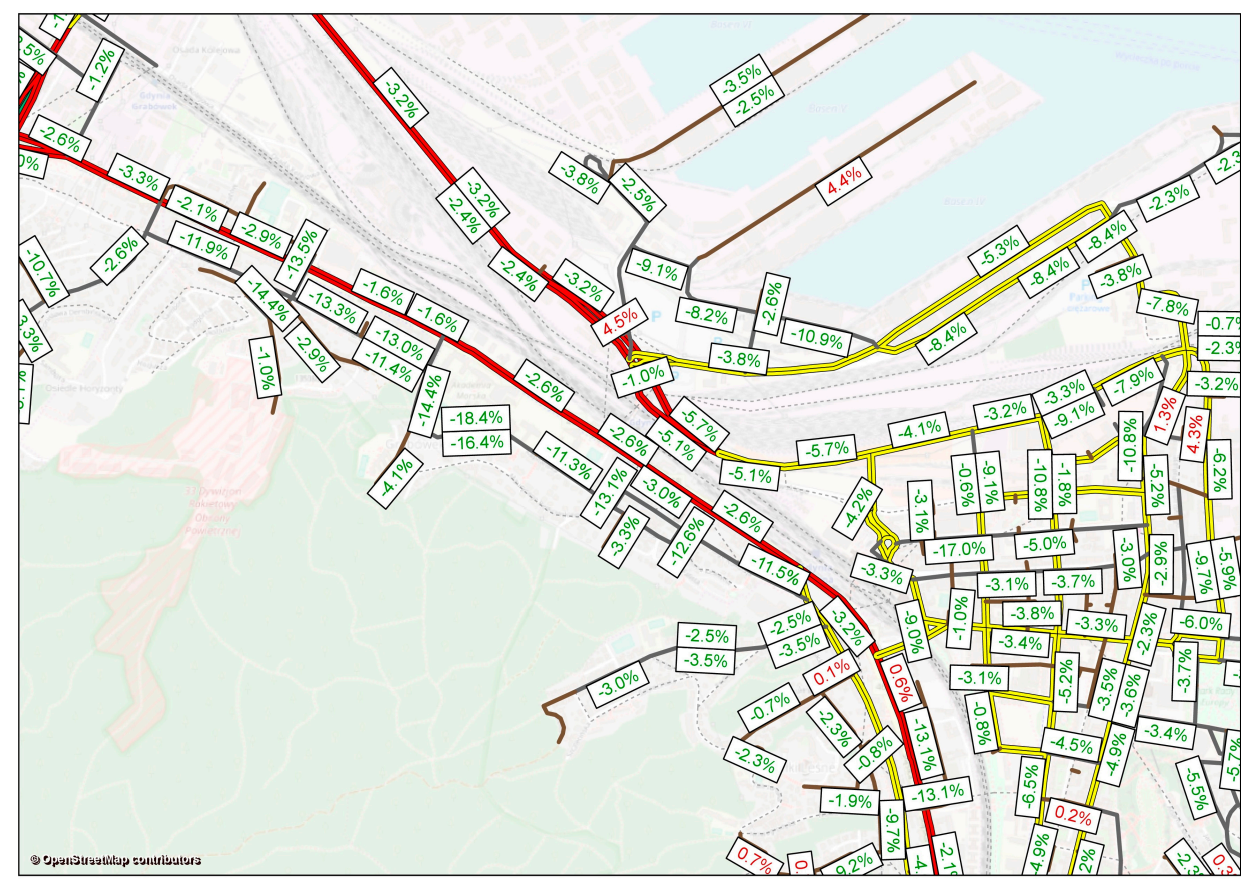

Figure 4. Change in traffic in scenario 1 compared to the baseline in one part of Gdynia.

Table 4. Examples of simulation results from the macroscopic model for selected variants of bus lanes for a selected mobility scenario.

\begin{tabular}{|c|c|c|c|c|c|}
\hline & & Unit & $\begin{array}{c}\text { Existing Traffic } \\
\text { Organization }\end{array}$ & $\begin{array}{l}\text { Road Section with } \\
\text { Bus Lane }\end{array}$ & Change \\
\hline \multirow{6}{*}{ 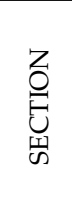 } & Passenger-kilometres travelled by $\mathrm{PT} *$ & [pkm] & 1053.7 & 1168.7 & $10.9 \%$ \\
\hline & Passenger-hours by PT & [pas-h] & 60.3 & 44.6 & $-26.1 \%$ \\
\hline & Average speed of PT & {$[\mathrm{km} / \mathrm{h}]$} & 17.5 & 26.2 & $50.1 \%$ \\
\hline & Passenger-kilometres travelled by cars & {$[\mathrm{pkm}]$} & 1348.7 & 1290.6 & $-4.3 \%$ \\
\hline & Passenger-hours by cars & [pas-h] & 41.9 & 41.8 & $-0.3 \%$ \\
\hline & Average speed of cars & {$[\mathrm{km} / \mathrm{h}]$} & 32.2 & 30.9 & $-4.0 \%$ \\
\hline \multirow{4}{*}{ 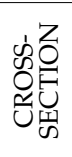 } & Passengers of PT & [pas.] & 1242 & 1354 & $9.0 \%$ \\
\hline & Persons in passenger cars & [pas.] & 1711 & 1683 & $-1.6 \%$ \\
\hline & Modal snlit & {$[\%]$} & 35 & 45 & $29.3 \%$ \\
\hline & Modal split & {$[\%]$} & 65 & 55 & $-15.6 \%$ \\
\hline \multirow{4}{*}{ 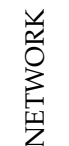 } & Passenger-kilometres travelled by PT & [pkm] & 485164 & 485268 & $0.0 \%$ \\
\hline & Passenger-hours by PT & [pas-h] & 17821 & 17393 & $-2.4 \%$ \\
\hline & Average speed of PT & {$[\mathrm{km} / \mathrm{h}]$} & 27.2 & 27.9 & $2.5 \%$ \\
\hline & Share of PT in modal split & {$[\%]$} & 39.04 & 39.37 & $0.9 \%$ \\
\hline
\end{tabular}


At the mesoscopic level, more detail was added about the transport network on the analysed sections, including traffic signal control and journey time information provided via Variable Message Signs. This affects the capacity of the sections and causes motorists to change trip routes. Simulations were conducted to help to calculate the change in global journey time of private car users for the entire transport network, change in vehicle kilometres travelled and emissions (Table 5).

Table 5. Example of simulation results from mesoscopic model for selected variant of bus lane introduction for a selected mobility scenario-effect for the area of entire city, afternoon peak hour.

\begin{tabular}{cccccccc}
\hline Variant & $\begin{array}{c}\text { Veh-km } \\
\text { Travelled } \\
(\mathbf{v e h}-\mathbf{k m})\end{array}$ & $\begin{array}{c}\text { Travel } \\
\text { Time } \\
(\mathbf{v e h - h )}\end{array}$ & $\begin{array}{c}\text { Fuel } \\
\text { Consumption } \\
\mathbf{( L )}\end{array}$ & $\begin{array}{c}\text { Mean } \\
\text { Speed } \\
(\mathbf{k m} / \mathbf{h})\end{array}$ & $\begin{array}{c}\text { Number } \\
\text { of Stops } \\
(-)\end{array}$ & $\begin{array}{c}\mathbf{C O}_{\mathbf{2}} \\
\text { Emission } \\
\mathbf{( k g )}\end{array}$ & $\begin{array}{c}\mathbf{N O}_{\mathbf{x}} \\
\text { Emission } \\
\mathbf{( k g )}\end{array}$ \\
\hline Existing & $249,893.1$ & 6310.4 & $22,664.8$ & 39.6 & $212,679.1$ & $21,764.0$ & 529.8 \\
With bus lane & $250,429.7$ & 6620.3 & $23,830.2$ & 37.8 & $220,601.6$ & $22,151.1$ & 526.9 \\
\% change & $0.21 \%$ & $4.91 \%$ & $5.14 \%$ & $-4.48 \%$ & $3.73 \%$ & $1.78 \%$ & $-0.55 \%$ \\
\hline
\end{tabular}

Thanks to microsimulation models a more accurate representation of the traffic situation was possible including a number of parameters such as driver behaviour, vehicle interaction (car following model, lane change model), vehicle size, technical parameters of a section, traffic organisation, traffic lights programme within the traffic control system, etc. The achieved accuracy helped to develop a detailed traffic organisation if dedicated bus lanes were to be provided on specific sections. Analysis was also possible of how this would affect traffic conditions and user behaviour (Table 6). In addition, the end result of the simulation, i.e., graphic representation of the specific traffic organisation, was presented during public consultation. It helped the residents to understand how the proposed measure would change traffic on that road section.

Table 6. Example of simulation results from the microscopic model for a selected variant of a bus lane-effect for the analysed road section.

\begin{tabular}{cccccc}
\hline & \multicolumn{2}{c}{ Existing Traffic Organization } & \multicolumn{2}{c}{ Road Section with Bus Lane } & \% Change in \\
\cline { 2 - 5 } & $\begin{array}{c}\text { Mean Travel } \\
\text { Time (s) }\end{array}$ & $\begin{array}{c}\text { Mean Travel } \\
\text { speed (km/h) }\end{array}$ & $\begin{array}{c}\text { Mean Travel } \\
\text { Time (s) }\end{array}$ & $\begin{array}{c}\text { Mean Travel } \\
\text { speed (km/h) }\end{array}$ & $\begin{array}{c}\text { Travel Time } \\
\text { Private transport }\end{array}$ \\
\hline Public transport & 251.2 & 32.7 & 222.3 & 33.7 & $13.0 \%$ \\
\hline
\end{tabular}

Conducted at different levels, the analyses helped to select the variant which offered the best benefit to cost relation [56]. That particular variant was implemented as a result of the SUMP process.

\subsection{Support of the Participation Process with MST}

The participatory approach is fundamental to the SUMP process [57]. Stakeholder and citizen involvement is an important step in the SUMP process (Figure 1). The approach expresses a new paradigm and puts the focus on the social context of mobility planning [58].

Civic participation involves the active stakeholder engagement from early on, when diagnostic work first begins. A communication plan must be drawn up to address the particular stakeholders, local specificity and ways to interact (e.g., IT tools will probably be of limited use when interacting with older people).

Gdynia's choice of stakeholders for work on the mobility plan was related to the social context. Stakeholders were selected based on their relations with the local authorities ("internal" and "external"). The first category included members of City Hall staff, in particular employees of departments responsible for land use, transport and mobility, economic development, social policy and education. To reflect the city's character, stakeholders also included public transport organisations (public transport authorities, operators) and transport and logistics organisations 
(i.e., port authority, railway sector). Education sector organisations (pre-schools and schools) formed a separate a group of "internal" stakeholders. "External" stakeholders included business and non-governmental organisations.

Engaging the public presented a certain challenge, especially in the early stages. The tools used to involve and communicate with residents included meetings, marketing research on transport behaviour and preferences, use of a web 2.0 platform-i.e., Mobilna Gdynia, the city's official mobility portal which was used for mobility education, on-line surveys, public participation and as a dissemination tool. One of the tasks of the portal was to keep the public informed and consult residents on planned improvements such as priority bus lanes, using the results of the microsimulation model, i.e. visualisations (Figure 5). The ability to present modelling results by visualising traffic on specific road network sections was an attractive option and helped the public to better understand the proposed improvement and its effect on traffic.

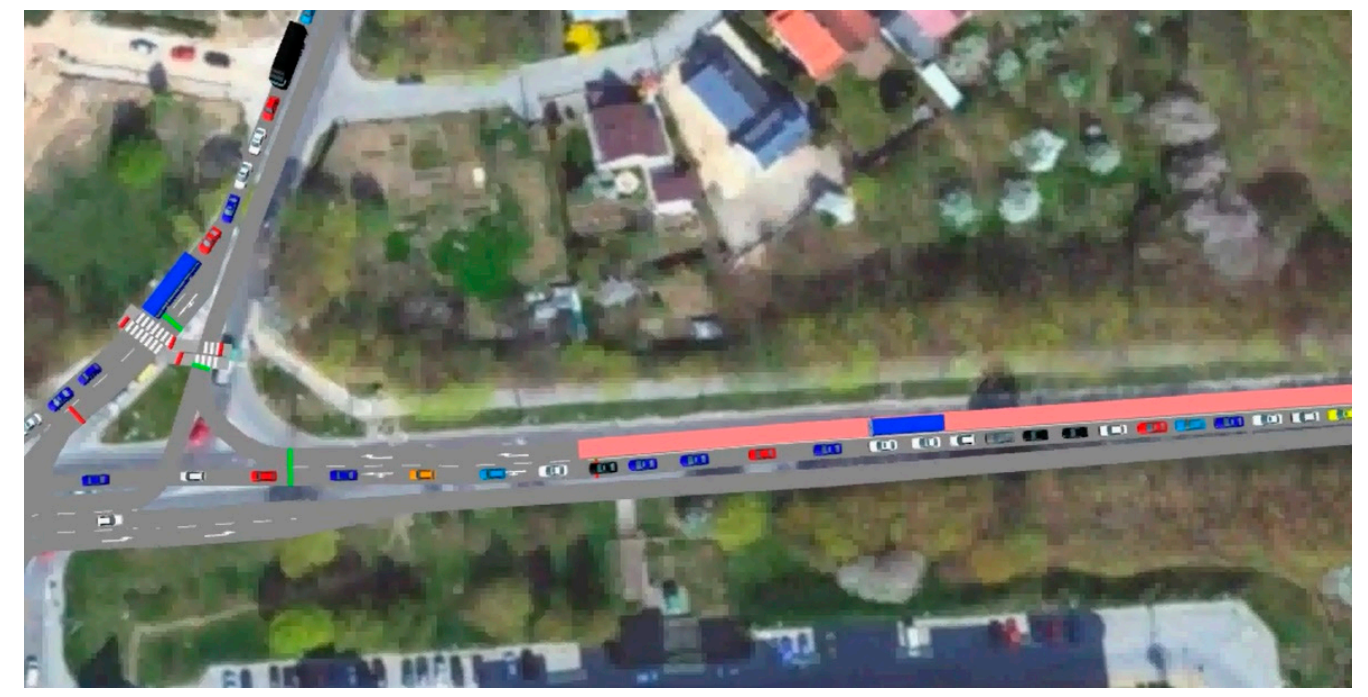

Figure 5. Visualisation of simulation results for a selected variant of a bus lane in Gdynia.

The multilevel traffic model was used throughout the SUMP process at different stages and by different stakeholders (Table 7). The model presents further potential for different analyses to support decision making in spatial planning and feasibility studies of infrastructural projects. However, to make the participatory process more effective at the final stage, a variety of different decision-support methods can be used such as group multicriteria decision-making methods, focus groups, mega focus groups, Multi Actor MCDM methods, public participation GIS, Social Network Analysis, Discrete Choice Models and Agent Based Models [25]. In particular, public participation GIS combined with other methods can be helpful in deciding on the locations of specific investment and/or modernisation projects [26]. This is aided by the advances in computer technology [27] which helps to embed qualitative data in space [59].

Table 7. The use of the MST in the stakeholder engagement process.

\begin{tabular}{cccl}
\hline Stakeholder & $\begin{array}{c}\text { Type of } \\
\text { Stakeholder }\end{array}$ & Level & \multicolumn{1}{c}{ Application } \\
\hline city hall members & internal & macro & $\begin{array}{l}\text { presentation of scenario effects during political procedures } \\
\text { traffic and public transport analysis, transport system } \\
\text { planning } \\
\text { tactical and operational level analyses, planning new traffic } \\
\text { layouts, traffic control, temporary traffic layouts during road } \\
\text { works, mass events, data for economic analyses }\end{array}$ \\
\hline road authority & macro & internal, model \\
operator & meso, micro & &
\end{tabular}


Table 7. Cont.

\begin{tabular}{|c|c|c|c|}
\hline Stakeholder & $\begin{array}{c}\text { Type of } \\
\text { Stakeholder }\end{array}$ & Level & Application \\
\hline spatial planning unit & internal & macro & $\begin{array}{l}\text { approval of proposed changes in public transport system } \\
\text { and provision of input data for spatial planning }\end{array}$ \\
\hline public transport authority & internal & macro & $\begin{array}{l}\text { approval of proposed changes in public transport system } \\
\text { and provision of data for transport demand analysis }\end{array}$ \\
\hline $\begin{array}{l}\text { other public institutions } \\
\text { independent from city } \\
\text { authorities }\end{array}$ & external & $\begin{array}{l}\text { macro, meso, } \\
\quad \text { micro }\end{array}$ & $\begin{array}{l}\text { approval of proposed changes in transport system, } \\
\text { presentation and consultation for the proposed } \\
\text { infrastructural solutions, transport organisation }\end{array}$ \\
\hline Stakeholders-the public & external & micro & presentation of road traffic solutions (i.e., bus lanes) \\
\hline NGOs & external & micro & presentation of road traffic solutions (i.e., bus lanes) \\
\hline
\end{tabular}

\section{Discussion and Conclusions}

The SUMP is recommended by the European Commission as an effective transport policy tool. A number of European cities are now embarking on the mobility planning process and following the EC's guidelines [18] by engaging decision-makers, stakeholders and communities. Decisions and planning proposals can receive effective help from transport models as demonstrated in this paper. The model gives a better understanding of how the transport system will behave for different mobility scenarios. While transport models have a long history of being a major tool in transport policy making [30], cities fail to use their full potential $[30,60,61]$. The reasons for this vary and may include a lack of cooperation between the relevant bodies or the perceived importance among decision-makers and stakeholders of what the models can offer [30].

If used in the SUMP process, the transport model supplies hard data in the form of quantitative outcomes. As a result, ex ante evaluations can be made of the effects of decisions taken at different levels (strategic, tactical and operational). The decisions involve concrete targets, policies and detailed solutions. If there are no models or none is used, effectiveness evaluations are subjective or based on assumptions. Availability of hard data from a simulation and visualisations conducted in a transport model are particularly important when city authorities plan to engage local communities in public consultation, a process which is an essential part of the SUMP process [18]. If they can be visualised, the outcomes of analyses are easier to understand for the public and can significantly improve the public participation process, especially as a complement to other decision-support tools and methods [25-28].

The paper proposes a method for integrating a multilevel transport model into the SUMP process. If used for decision-making and project work, the model helps to understand the changes that will occur in a particular city development scenario, link mobility with land use and give clarity about how the objectives will change transport behaviour. Because it uses an integrated multilevel structure (macro, meso and microscopic modelling), the MST can be used at almost any stage of the SUMP process, for analyses at different planning levels (strategic, tactical, operational) and for different levels of detail. The multilevel model can be used for public consultation, a function which is not sufficiently appreciated but works very well when e.g., seeking agreement on a new traffic layout. The ability to share with communities and decision-makers graphic representations of complicated engineering and management issues is very helpful. Achieved thanks to the microscopic layer, visualisations also help with understanding the consequences of measures. Even though the MST must first be built or adapted which requires planning and spending, it benefits the SUMP process greatly and should therefore be recommended to cities embarking on the mobility planning process.

As we know from the literature, the participatory approach which is one of the SUMP process's special features, is often presented in contrast to the technical approach, a synonym for the traditional approach to planning transport. One of its characteristic features is that it uses traffic models. The article seeks to demonstrate that these approaches do not have to be contradictory and that the tools and quantitative methods can and should be used to improve SUMP stakeholder communications. 
However, not all cities have traffic models. Those that do, may need to update and improve them. If that is the case, the benefits described here make it worthwhile to consider building, improving and maintaining a transport model to support SUMP development and delivery.

Our methodology makes it clear that the macro model is the basic level and that it is good enough as a tool to support the SUMP process. If extended with the meso and micro level, the model offers additional benefits such as advanced analyses and a richer public consultation process. Because extending the model takes time, resources and data, the decision to use one in the SUMP process must be made after a careful analysis of costs and benefits. Cities that lack the resources to develop and maintain the model on their own, may consider using other tools or, which is what Gdynia did, secure outside financing. Once developed and kept updated, the model can serve many purposes, not only the SUMP and can be used by many city institutions. So, the cost should not be considered as entirely SUMP related.

The methodology presented in Section 3 has been applied to Gdynia's SUMP process. Building on the experience of this European city, the following conclusions can be formulated listing the advantages of having a transport model which is integrated into the SUMP process. It:

- increases the effectiveness of planning and decision-making within the SUMP process and enhances knowledge and engineering practice with hard data generated by transport model analyses,

- helps to conduct a quantitative effectiveness evaluation of a policy and vision and evaluate the outcomes of measures designed to meet SUMP targets,

- takes money and time which must be accounted for in the SUMP process budget and schedule to build a model or adapt it to the process; requires the engagement and cooperation of stakeholders responsible for model maintenance and services.

The case study in question shows the potential offered by the multilevel model (MST) in the SUMP process. It:

- helps to achieve transparent analysis results, regardless of the modelling or planning level thanks to integrated layers and mutual data exchange,

- helps to use the MST at each SUMP process stage; thanks to this, mobility scenarios can be selected and evaluated against a set of criteria; helps to define SMART objectives, select the most effective measures and solutions and develop SUMP monitoring indicators,

- offers a visual representation of analysis results which is particularly important in public consultation processes and helps to argue the case for SUMP-related decisions.

The conclusions show that the methods proposed in the article are worthwhile and cities considering the SUMP process would be well advised to apply them in their work. Because the city used the methods in its SUMP process, Gdynia's example shows that integrating the model has not only improved the SUMP process but can also be offered as good practice for other cities. This may be of particular importance in the context of cities in emerging economies with highly dynamic motorization rates. While sustainable urban mobility plans may not be considered today, the cities will soon have to rise to the challenge of balancing transport needs and transport behaviour.

Supplementary Materials: The following are available online at http:/ /www.mdpi.com/2071-1050/10/2/479/s1, Document S1: Sustainable Urban Mobility Plan for Gdynia for the years 2016-2025, Document S2: Report on HOV/ bus lanes in Gdynia, Document S3: Report on the traffic model development for SUMP.

Acknowledgments: The study was conducted under CIVITAS DYN@MO (DYNamic citizens @ctive for sustainable MObility) — a European project implemented between 2012-2016 under CIVITAS II PLUS, funded from the 7th Framework Programme of the European Commission. No funding was obtained in the project to cover the costs of Open Access publication.

Author Contributions: Aleksandra Romanowska and Romanika Okraszewska both wrote and edited the article, contributed to Section 1, Section 2.1, Section 3, Section 5, developed the method for integrating the model within the SUMP process; Marcin Wołek contributed to Section 1, Section 2.1, Section 4.1, Section 4.2, 
Section 4.4; Jacek Oskarbski and Krystian Birr both contributed to Section 2.2, Section 4.2, Section 4.3; Kazimierz Jamroz provided supervision and contributed to Section 5. All authors were directly involved in the SUMP process conducted with the use of the MST in Gdynia: Aleksandra Romanowska-SUMP process leader, Marcin Wołek-SUMP main author and CIVITAS DYN@MO project manager representing the University of Gdansk, Romanika Okraszewska-member of SUMP working team, Jacek Oskarbski-main author of the idea of MST in Gdynia, responsible for its development (CIVITAS DYN@MO measure leader representing the Gdansk University of Technology), Jacek Oskarbski and Krystian Birr-built the MST and used it for SUMP-related analyses, Kazimierz Jamroz-CIVITAS DYN@MO project manager representing the Gdansk University of Technology.

Conflicts of Interest: The authors declare no conflict of interest. The funding sponsors had no role in the design of the study, in the collection, analyses, or interpretation of data, nor to the writing of the manuscript or the decision to publish the results.

\section{References}

1. Berry, B.J.L. Urbanization. Available online: https://www.researchgate.net/publication/226167135_ Urbanization (accessed on 7 February 2018).

2. Lerner, W. The Future of Urban Mobility: Towards Networked, Multimodal Cities of 2050. Available online: https:/ / robertoigarza.files.wordpress.com/2009/07/rep-the-future-of-urban-mobility-2050-little2011.pdf (accessed on 7 February 2018).

3. Eurostat. Passenger Cars, by Type of Motor Energy. 2015. Available online: http:/ / ec.europa.eu/eurostat/ data / database (accessed on 7 February 2018).

4. BP Energy Outlook 2015. Available online: https://www.bp.com/en/global/corporate/energy-economics / energy-outlook.html (accessed on 7 February 2018).

5. Van Wee, B.; Ettema, D. Travel behaviour and health: A conceptual model and research agenda. J. Transp. Health 2016, 3, 240-248. [CrossRef]

6. European Commission DG MOVE. Study to Support an Impact Assessment of the Urban Mobility Package; Activity 31 Sustainable Urban Mobility Plans Final Report; European Commission DG MOVE: Brussels, Belgium, 2013.

7. Banister, D. The sustainable mobility paradigm. Transp. Policy 2008, 15, 73-80. [CrossRef]

8. Commission of the European Communities. Green Paper. Towards a New Culture for Urban Mobility; Commission of the European Communities: Brussels, Belgium, 2007.

9. Litman, T. Measuring transportation traffic, mobility and accessibility. ITE J. 2003, 73, 28-32.

10. Hickman, R.; Hall, P.; Banister, D. Planning more for sustainable mobility. J. Transp. Geogr. 2013, 33, $210-219$. [CrossRef]

11. Reisi, M.; Aye, L.; Rajabifard, A.; Ngo, T. Land-use planning: Implications for transport sustainability. Land Use Policy 2016, 50, 252-261. [CrossRef]

12. Cervero, R. Mixed land-uses and commuting: Evidence from the American housing survey. Transp. Res. Part A Policy Pract. 1996, 30, 361-377. [CrossRef]

13. Organisation for Economic Co-Operation and Development (OECD). Compact City Policies: A Comparative Assessment; OECD: Paris, France, 2012. [CrossRef]

14. Holden, E.; Høyer, K.G. The ecological footprints of fuels. Transp. Res. Part D Transp. Environ. 2005, 10, 395-403. [CrossRef]

15. Moriarty, P.; Honnery, D. Low-mobility: The future of transport. Futures 2008, 40, 865-872. [CrossRef]

16. Mallus, M.; Colistra, G.; Atzori, L.; Murroni, M.; Pilloni, V. Dynamic carpooling in urban areas: Design and experimentation with a multi-objective route matching algorithm. Sustainability 2017, 9, 254. [CrossRef]

17. Bruun, E.; Givoni, M. Sustainable mobility: Six research routes to steer transport policy. Nature 2015, 523, 29-31. [CrossRef] [PubMed]

18. Wefering, F.; Rupprecht, S.; Bührmann, S.; Böhler-Baedeker, S.; Granberg, M.; Vilkuna, J.; Saarinen, S.; Backhaus, W.; Laubenheimer, M.; Lindenau, M.; et al. Developing and Implementing a Sustainable Urban Mobility Plan Guidelines-Developing and Implementing a Sustainable Urban Mobility Plan Title: Guidelines. Developing and Implementing a Sustainable Urban Mobility Plan; European Commission: Brussels, Belgium, 2014.

19. Gavanas, N.; Pozoukidou, G.; Verani, E. Integration of LUTI models into sustainable urban mobility plans (SUMPs). Eur. J. Environ. Sci. 2016, 6, 11-17. [CrossRef]

20. Alonso, A.; Monzón, A.; Wang, Y. Modelling Land Use and Transport Policies to Measure Their Contribution to Urban Challenges: The Case of Madrid. Sustainability 2017, 9, 378. [CrossRef] 
21. European Commission. A Concept for Sustainable Urban Mobility Plans; European Commission: Brussels, Belgium, 2013.

22. Wallington, T.J.; Lambert, C.K.; Ruona, W.C. Diesel vehicles and sustainable mobility in the US. Energy Policy 2013, 54, 47-53. [CrossRef]

23. Sosa López, O.; Montero, S. Expert-citizens: Producing and contesting sustainable mobility policy in Mexican cities. J. Transp. Geogr. 2017. [CrossRef]

24. Schippl, J.; Gudmundsson, H.; Hedegaard Sørensen, C.; Anderton, K.; Brand, R.; Dotterud Leiren, M.; Reichenbach, M. Different pathways for achieving cleaner urban areas: A roadmap towards the white paper goal for urban transport. Transp. Res. Procedia 2016, 14, 2604-2613. [CrossRef]

25. Le Pira, M.; Marcucci, E.; Gatta, V.; Ignaccolo, M.; Inturri, G.; Pluchino, A. Towards a decision-support procedure to foster stakeholder involvement and acceptability of urban freight transport policies. Eur. Transp. Res. Rev. 2017, 9, 54. [CrossRef]

26. Piantanakulchai, M.; Saengkhao, N. Evaluation of alternatives in transportation planning using multi-stakeholders multi-objectives AHP modelling. Proc. East. Asia Soc. Transp. Stud. 2003, 4, 1613-1628.

27. Tang, K.X.; Waters, N.M. The internet, GIS and public participation in transportation planning. Prog. Plan. 2005, 64, 7-62. [CrossRef]

28. Zhong, T.; Young, R.K.; Lowry, M.; Rutherford, G.S. A model for public involvement in transportation improvement programming using participatory Geographic Information Systems, Comput. Environ. Urban Syst. 2008, 32, 123-133. [CrossRef]

29. Banister, D. Cities, mobility and climate change. J. Transp. Geogr. 2011, 19, 1538-1546. [CrossRef]

30. Givoni, M.; Beyazit, E.; Shiftan, Y. The use of state-of-the-art transport models by policymakers-Beauty in simplicity? Plan. Theory Pract. 2016, 17, 385-404. [CrossRef]

31. Joint Assistance to Support Projects in European Regions (JASPERS). The Use of Transport Models in Transport Planning and Project Appraisal, JASPERS Appraisal Guidance (Transport). Available online: http:/ / kc-sump.eu/wordpress/wp-content/uploads/2015/04/Upotreba-Modela-u-prometnomplaniranju_JASPERS_kolovoz-2014.pdf (accessed on 7 February 2018).

32. May, A.D.; Shepherd, S.P.; Timms, P.M. Optimal transport strategies for European cities. Transportation 2000, 27, 285-315. [CrossRef]

33. Kaparias, I.; Zavitsas, K.; Bell, M.G.H. State-of-the-Art of Urban Traffic Management Policies and Technologies; Imperial College London: London, UK, 2010.

34. Boile, M.P.; Ozbay, K. The Future of Transportation Modeling; New Jersey Department of Transportation, Federal Highway Administration: West Trenton, NJ, USA, 2005.

35. WSP Parsons Brinckerhoff, "Planning Techniques" Transport modelling for SUMP—Why, What, When and How Much? Available online: http:/ / www.eltis.org/sites/default/files/16-06-2015_b_jordanou_brasov_ sump.pdf (accessed on 7 February 2018).

36. West Yorkshire Local Transport Plan 2006/7 to 2010/11. Available online: https:/ /www.wymetro.com/ media/1400/1tp2-main-document.pdf (accessed on 7 February 2018).

37. Sivakumar, A. Modelling transport: A Synthesis of Transport Modelling Methodologies; Imperial College London: London, UK, 2007.

38. Travel Model Improvement Program (U.S.); Barton-Aschman Associates; Cambridge Systematics, Model validation and reasonableness checking manual (U.S. Depertment of Transportation, Federal Highway Administration, Federal Transit Administration, Assistant Secretary for Transportation Policy, 2001). Available online: https:/ / babel.hathitrust.org/cgi/pt?id=ien.35556030756969; view=1up;seq=3 (accessed on 7 February 2018).

39. Singh, R.; Dowling, R. Improved speed-flow relationships: Application to transportation planning models. In Proceedings of the Seventh TRB Conference on the Application of Transportation Planning Methods, Boston, MA, USA, 7-11 March 1999; pp. 340-349.

40. Macioszek, E.; Sierpiński, G.; Czapkowski, L. Methods of Modeling the Bicycle Traffic Flows on the Roundabouts. In International Conference on Transport Systems Telematics; Springer: Berlin, Germany, 2010; pp. 115-124. [CrossRef]

41. Smith, J.; Blewitt, R. Traffic Modelling Guidelines. Traffic Manager and Network Performance Best Practice. Version 3 (Transport for London, 2010). Available online: http://content.tfl.gov.uk/traffic-modellingguidelines.pdf (accessed on 7 February 2018). 
42. Dimitriou, H.T.; Thompson, R. Strategic Planning for Regional Development in UK; Routledge: Abingdon, UK, 2008.

43. Bliemer, M.C.J.; Mulley, C.; Moutou, C.J. Handbook on Transport and Urban Planning in the Developed World. Transp. Rev. 2016, 36, 816-817.

44. Oskarbski, J.; Zawisza, M.; Miszewski, M. Information system for drivers within the integrated traffic management system-TRISTAR. In International Conference on Transport Systems Telematics; Springer: Berlin, Germany, 2015; pp. 131-140. [CrossRef]

45. Kumar, P.; Merzouki, R.; Conrard, B.; Coelen, V.; Ould Bouamama, B. Multilevel Modeling of the Traffic Dynamic. IEEE Trans. Intell. Transp. Syst. 2014, 15, 1066-1082. [CrossRef]

46. Williams, H.C.W.L. On the Formation of Travel Demand Models and Economic Evaluation Measures of User Benefit. Environ. Plan. A 1977, 9, 285-344. [CrossRef]

47. ZKM Gdynia. Transport Preferences and Behaviour of Residents of Gdynia; Marketing Survey Report 2015; ZKM Gdynia: Gdynia, Poland, 2015.

48. Czapnik, M.; Czermański, E.; Franek, Ł.; Furkal, J.; Hebel, K.; Jagiełło, A.; Kaszubowski, D.; Kuropatwiński, P.; Lewandowski, K.; et al. Sustainable Urban Mobility Plan for Gdynia; Wołek, M., Ed.; Civitas Dyn@mo: Gdynia, Poland, 2016.

49. CIVITAS DYN@MO Webpage. Available online: http://civitas.eu/content/dynmo (accessed on 7 February 2018).

50. Ortúzar, J.D.D.; Willumsen, L.G. Modelling Transport, 4th ed.; John Wiley \& Sons: Hoboken, NJ, USA, 2011.

51. Gdynia's, S.U.M.P.; Oskarbski, J.; Jamroz, K.; Budziszewski, T.; Birr, K.; Oskarbski, G.; Gumińska, L.; Oskarbska, I.; Michalski, L.; Smolarek, L.; et al. Report on the Traffic Model Development for SUMP; Implementation Status Report G3.1, Civitas Dyn@mo Project; Gdansk University of Technology: Gdańsk, Poland, 2016.

52. Annema, J.A.; De Jong, M. The History of the Transport Future-Evaluating Dutch Transport Scenarios of the Past. Transp. Rev. 2011, 31, 341-356. [CrossRef]

53. Wilkinson, A.; Kupers, R. Living in the futures: How scenario planning changed corporate strategy. Harv. Bus. Rev. 2013, 91, 3-11.

54. Gunnarson-Östling, U.; Höjer, M. Scenario planning for sustainability in Stockholm, Sweden: Environmental justice considerations. Int. J. Urban Reg. Res. 2011, 35, 1048-1067. [CrossRef]

55. Grzelec, K.; Hebel, K.; Wyszomisrki, O. A Guide to Developing Sustainable Urban Mobility Plans; Wołek, M., Ed.; University of Gdansk Development Foundation: Gdańsk, Poland, 2016.

56. Wołek, M.; Oskarbski, J.; Polakowski, R.; Birr, K. Report on HOV/Bus Lanes in Gdynia Implementation Status Report G3.5; Civitas Dyn@mo: Gdynia, Poland, 2016.

57. Lindenau, M.; Böhler-Baedeker, S. Citizen and Stakeholder Involvement: A Precondition for Sustainable Urban Mobility. Transp. Res. Procedia 2014, 4, 347-360. [CrossRef]

58. Arsenio, E.; Martens, K.; Di Ciommo, F. Sustainable urban mobility plans: Bridging climate change and equity targets? Res. Transp. Econ. 2016, 55, 30-39. [CrossRef]

59. Salonen, M.; Broberg, A.; Kyttä, M.; Toivonen, T. Do suburban residents prefer the fastest or low-carbon travel modes? Combining public participation GIS and multimodal travel time analysis for daily mobility research. Appl. Geogr. 2014, 53, 438-448. [CrossRef]

60. Banister, D.; Hickman, R. Transport futures: Thinking the unthinkable. Transp. Policy. 2013, 29, $283-293$. [CrossRef]

61. Gudmundsson, H. Analysing Models as a Knowledge Technology in Transport Planning. Transp. Rev. 2011, 31, 145-159. [CrossRef]

(C) 2018 by the authors. Licensee MDPI, Basel, Switzerland. This article is an open access article distributed under the terms and conditions of the Creative Commons Attribution (CC BY) license (http:/ / creativecommons.org/licenses/by/4.0/). 